\title{
Crescimento, produção e acúmulo de potássio em bananeira 'Galil 18' sob irrigação e fertilização potássica
}

\author{
Flávio da Silva Costa(1), Eugênio Ferreira Coelho(2), Ana Lúcia Borges ${ }^{(2)}$, Arthur José Mendes Pamponet( ${ }^{(3)}$, \\ Afrânio dos Anjos Santos Mendes da Silva( ${ }^{(3)}$ e Nilo Ferreira de Azevedo(3)
}

\begin{abstract}
(1)Universidade Federal de Campina Grande, Rua Rodrigues Alves, oo 1.971, Bairro Universitário, CEP 58429-145 Campina Grande, PB. E-mail: flaviocostapb@yahoo.com.br (2)Embrapa Mandioca e Fruticultura, Rua Embrapa, s/no, CEP 44380-000 Cruz das Almas, BA. E-mail: eugenio@cnpmf.embrapa.br, analucia@cnpmf.embrapa.br ${ }^{(3)}$ Universidade Federal do Recôncavo da Bahia, Rua Rui Barbosa, no 710, Centro, CEP 44380-000 Cruz das Almas, BA. E-mail: arthurpamponet@gmail.com, afranio_anjos@hotmail.com, nilo270@hotmail.com
\end{abstract}

Resumo - O objetivo deste trabalho foi avaliar o crescimento vegetativo, as variáveis de produção e o acúmulo de potássio na parte aérea da bananeira, cultivar Galil 18, sob diferentes níveis de irrigação e de potássio, nas condições de tabuleiro costeiro do Estado da Bahia. Utilizou-se o delineamento experimental de blocos ao acaso, em esquema fatorial 4x4 (lâminas de irrigação x doses de potássio), com três repetições. As lâminas de irrigação se basearam em 30, 60, 90 e $120 \%$ da evapotranspiração de referência (ETo). As doses de $\mathrm{K}_{2} \mathrm{O}$ foram de $0,400,800$ e $1.200 \mathrm{~kg} \mathrm{ha}^{-1}$. Determinaram-se o crescimento vegetativo, as variáveis de produção e o acúmulo de $\mathrm{K}$ nos diversos órgãos da parte aérea da planta. As doses de potássio não influenciaram significativamente as variáveis de crescimento e de produção. As lâminas de irrigação tiveram efeito significativo na altura e no diâmetro do pseudocaule, no número de frutos por cacho, na produtividade e na eficiência do uso da água. O pseudocaule é o maior depositário de $\mathrm{K}$ na bananeira.

Termos para indexação: Musa, eficiência de uso, fertirrigação, nutrição mineral, suprimento hídrico.

\section{Growth, yield and potassium accumulation in 'Galil 18' banana under irrigation and potassium fertilization}

\begin{abstract}
The objective of this work was to evaluate the vegetative growth, yield variables and the accumulation of potassium in the aerial part of the banana, cultivar Galil 18, under different irrigation and potassium levels in the conditions of the coastal tablelands of Bahia state, Brazil. The experimental design was a completely randomized block, in a $4 \times 4$ factorial arrangement (irrigation levels $\mathrm{x}$ potassium doses), with three replicates. Irrigation water depths were based on $30,60,90$ and $120 \%$ of the reference evapotranspiration (ETo). The $\mathrm{K}_{2} \mathrm{O}$ doses were $0,400,800$ and $1,200 \mathrm{~kg} \mathrm{ha}^{-1}$. Vegetative growth, production variables and $\mathrm{K}$ accumulation by the several organs of the aerial portion of the plant were determined. Potassium doses did not significantly affect growth and production variables. Irrigation water depth had a significant effect on the height and diameter of the pseudo-stem, on the number of fruits per bunch, on yield and on water use efficiency. The pseudo-stem is the largest $\mathrm{K}$ repository in banana plants.
\end{abstract}

Index terms: Musa, use efficiency, fertirrigation, mineral nutrition, hydric reposition.

\section{Introdução}

Em 2009, o Brasil produziu aproximadamente 7,2 milhões de toneladas de banana (Musa sp.), sendo considerado o quinto maior produtor mundial, após Índia, Filipinas, China e Equador (Food and Agriculture Organization of the United Nations, 2011). No entanto, a produtividade nacional tem se mostrado muito aquém de seu potencial, principalmente em razão de problemas nutricionais e de suprimento hídrico, apesar da existência de condições favoráveis para o seu cultivo em quase todo o país.
A cultura da banana na região Nordeste está condicionada à reposição contínua de água pela irrigação, nos períodos de estiagem. Desse modo, a quantidade adequada de água a ser aplicada vem sendo avaliada por vários autores (Coelho et al., 2006; Figueiredo et al., 2007; Azevedo \& Bezerra, 2008; Braga Filho et al., 2008), uma vez que tanto o deficit como o excesso de água no solo provocam quedas na produtividade da bananeira (Jaimez et al., 2005).

$\mathrm{O} \mathrm{K}$ normalmente é suprido pela adubação convencional ou via água de irrigação. De acordo com Teixeira et al. (2011), a absorção desse nutriente 
pela planta torna-se mais eficiente em áreas irrigadas, especialmente sob fertirrigação. A bananeira produz quantidades elevadas de matéria seca e acumula altos teores de nutrientes em seus órgãos, principalmente $\mathrm{K}$, que é o nutriente absorvido em maior quantidade pela planta (Neves et al., 1991). A absorção de K pela bananeira é função da grande quantidade de matéria seca produzida pela planta, já que existe distribuição homogênea do nutriente em seus órgãos (Hoffmann et al., 2010). Segundo Moreira \& Fageria (2009), o acúmulo total de $\mathrm{K}$ na parte aérea da bananeira cultivar Thap Maeo é maior no pseudocaule, seguido de frutos, folhas, engaço + brácteas e restos florais.

Há vários estudos com avaliação dos efeitos da aplicação de $\mathrm{K}_{2} \mathrm{O}$, via fertirrigação, sobre variáveis de crescimento e de produção de bananeira do grupo Prata (Pinto et al., 2005; Santos et al., 2009; Melo et al., 2010b; Barroso et al., 2011). Contudo, não há conhecimento de relatos a respeito da interação entre fertilização potássica e lâminas de irrigação, nas condições edafoclimáticas do recôncavo baiano.

A bananeira 'Galil 18' é um híbrido tetraploide AAAB de Prata-Anã (subgrupo Prata), que tem se mostrado resistente à sigatoka-negra, moderadamente suscetível à sigatoka-amarela e tolerante ao mal-do-Panamá. No Brasil, a maior área plantada com a 'Galil 18' encontra-se no Vale do Ribeira, SP. Entretanto, são escassas as informações sobre resultados científicos relacionados às variáveis crescimento, produção e acúmulo de potássio para essa cultivar, principalmente sob irrigação.

O objetivo deste trabalho foi avaliar o crescimento vegetativo, as variáveis de produção e o acúmulo de potássio na parte aérea da bananeira, cultivar Galil 18, sob diferentes níveis de água e de potássio, nas condições de tabuleiro costeiro do estado da Bahia.

\section{Material e Métodos}

O experimento foi realizado de julho de 2009 a novembro de 2010, em área experimental da Embrapa Mandioca e Fruticultura, no Município de Cruz das Almas, BA $\left(12^{\circ} 48^{\prime} \mathrm{S}\right.$ e $39^{\circ} 06^{\prime} \mathrm{W}$, a $225 \mathrm{~m}$ de altitude). O clima da região é úmido a subúmido, com pluviosidade média anual de $1.200 \mathrm{~mm}$. O solo da área experimental é classificado como Latossolo Amarelo álico, de textura média, com densidade de $1,5 \mathrm{~g} \mathrm{~cm}^{-3}$ e umidade correspondente à capacidade de campo e ao ponto de murcha permanente de $0,26 \mathrm{~m}^{3} \mathrm{~m}^{-3} \mathrm{e}$
$0,16 \mathrm{~m}^{3} \mathrm{~m}^{-3}$, respectivamente (Souza \& Souza, 2001). Os dados meteorológicos relativos ao primeiro ciclo da cultivar Galil 18 encontram-se na Tabela 1.

A análise química do solo indicou, para as profundidades de $0,3-0,7 \mathrm{~m}$, os seguintes atributos, respectivamente: $\mathrm{pH}\left(\mathrm{H}_{2} \mathrm{O}\right) 5,9$ e 4,6;2,0 e $1,7 \mathrm{mg} \mathrm{dm}^{-3}$ de P; 53 e $29 \%$ de V; 0,24 e 0,21 cmol $_{\mathrm{c}} \mathrm{dm}^{-3}$ de $\mathrm{K} ; 1,5$ e $0,8 \mathrm{cmol}_{\mathrm{c}} \mathrm{dm}^{-3}$ de $\mathrm{Ca} ; 1,2$ e $0,6 \mathrm{cmol}_{\mathrm{c}} \mathrm{dm}^{-3}$ de $\mathrm{Mg} ; 0$ e $0,9 \mathrm{cmol}_{\mathrm{c}} \mathrm{dm}^{-3}$ de Al; 0,28 e $0,12 \mathrm{cmol}_{\mathrm{c}} \mathrm{dm}^{-3} \mathrm{de} \mathrm{Na}$; 2,86 e 4,29 $\mathrm{cmol}_{\mathrm{c}} \mathrm{dm}^{-3} \mathrm{de} \mathrm{H}+\mathrm{Al} ; 3,29$ e $1,73 \mathrm{cmol}_{\mathrm{c}} \mathrm{dm}^{-3}$ de $\mathrm{S}$; e 6,15 e $6,02 \mathrm{cmol}_{\mathrm{c}} \mathrm{dm}^{-3} \mathrm{de}$ CTC.

A cultivar Galil 18 foi conduzida, durante o primeiro ciclo, em espaçamento de 3,0 m entre fileiras duplas, 2,0 $\mathrm{m}$ entre fileiras simples e 2,5 $\mathrm{m}$ entre plantas, com seis plantas úteis por parcela, o que totalizou área útil de $45 \mathrm{~m}^{2}$. Utilizou-se o delineamento experimental de blocos ao acaso, em arranjo fatorial $4 \times 4$ (lâminas de irrigação $x$ doses de $\mathrm{K}_{2} \mathrm{O}$ ), com três repetições. As lâminas de irrigação foram baseadas em 30, 60, 90 e $120 \%$ da evapotranspiração de referência (ETo). A determinação das lâminas foi realizada com base nos dados agrometeorológicos coletados diariamente em estação automática situada próximo à área experimental. Em seguida, determinou-se a ETo por meio do modelo de Penman-Monteith padronizado por Allen et al. (1998). Para determinação da evapotranspiração da cultura (ETc), utilizou-se o coeficiente de cultura da bananeira (Kc), conforme Coelho et al. (2006).

As doses de potássio aplicadas foram de 0, 400, 800 e $1.200 \mathrm{~kg} \mathrm{ha}^{-1}$, tendo-se utilizado nitrato de potássio $\left(\mathrm{KNO}_{3}\right)$ como fonte potássica. $\mathrm{O}$ manejo da irrigação foi realizado com base nos parâmetros de umidade do solo, por meio de reflectômetro TDR 100, (Campbell Scientific, Logan, UT, EUA) previamente calibrado para o solo da área experimental. As sondas foram instaladas a $0,3 \mathrm{~m}$ de profundidade e a $0,3 \mathrm{~m}$ de distância da planta, tendo-se realizado leituras diárias. Utilizou-se o sistema de irrigação localizada com três gotejadores de $4,0 \mathrm{~L} \mathrm{~h}^{-1}$ por planta, espaçados a $0,5 \mathrm{~m}$, com emissor junto à planta.

A adubação de fundação foi composta de $250 \mathrm{~g}$ de $\mathrm{P}_{2} \mathrm{O}_{5}, 90 \mathrm{~g}$ de FTE e $10 \mathrm{~L}$ de esterco de curral curtido em cada cova. A ureia foi utilizada para suprir a necessidade de nitrogênio no solo, segundo Borges \& Oliveira (2000). A fertirrigação foi iniciada três meses após a implantação do experimento e realizada semanalmente com uso de bomba injetora de acionamento hidráulico com diafragma. 
Coletaram-se, mensalmente, amostragens de solução do solo por meio de extrator de $1 \frac{1}{2} "$, (Sondaterra, Piracicaba, SP) instalados a $0,3 \mathrm{~m}$ de distância da planta e a $0,3 \mathrm{~m}$ e a $0,7 \mathrm{~m}$ de profundidade, para determinar as concentrações de potássio na zona radicular efetiva $(0,3 \mathrm{~m})$ e abaixo $(0,7 \mathrm{~m})$, o que permitiu identificar possíveis lixiviações do nutriente. Três horas após as fertirrigações, procedeu-se à sucção nos extratores, com bomba de vácuo a $-70 \mathrm{kPa}$, para absorção da solução do solo.

As variáveis de crescimento da bananeira foram: altura de planta, do solo à roseta foliar; diâmetro do pseudocaule a $0,20 \mathrm{~m}$ do solo; número de folhas funcionais (folhas com mais de $50 \%$ de área verde); e área foliar no florescimento, obtida por meio da equação proposta por Zucoloto et al. (2008): AFTe $=0,5187 \times(\mathrm{C} \times \mathrm{L} \times \mathrm{N})+9603,5$; em que: AFTe é a área foliar total $\left(\mathrm{cm}^{2}\right)$; C é o comprimento da terceira folha $(\mathrm{cm})$; L é a largura da terceira folha $(\mathrm{cm})$; e N é o número de folhas por planta.

Para a caracterização das variáveis de produção, avaliaram-se a produtividade e o número de pencas e de frutos por cacho. A eficiência do uso da água (EUA) foi determinada pela relação entre produtividade e lâmina líquida aplicada (irrigação + precipitação), conforme Oliveira et al. (2012).
Para determinar a massa de matéria seca e a absorção do potássio do solo por cada órgão da parte aérea da bananeira, coletaram-se, em uma planta de cada parcela, amostras de pseudocaule, folhas (pecíolo + limbo + nervuras), pencas, engaço e coração. As amostras foram secadas em estufa a $65^{\circ} \mathrm{C}$ até atingirem peso constante. Em seguida, determinouse a massa de matéria seca de cada órgão, por meio de balança semianalítica BL 3200H, (Shimadzu, São Paulo, SP) (Hoffmann et al., 2010). Os teores de K de cada órgão da planta foram obtidos segundo Malavolta et al. (1997).

A massa de matéria seca do pseudocaule foi estimada a partir de seu volume e massa específica, obtida a partir de três discos de $0,1 \mathrm{~m}$ de espessura, coletados no meio e nas extremidades do pseudocaule, cortado rente ao solo e considerado até a roseta foliar. Os discos foram pesados em balança semianalítica BL $3200 \mathrm{H}$, (Shimadzu, São Paulo, SP), tendo-se determinado o seu volume por meio de imersão em água. Em seguida, os discos foram levados para secagem em estufa a $65^{\circ} \mathrm{C}$, para determinação da matéria seca. De cada disco, foi retirada uma fatia correspondente a $1 / 4$ de seu volume, de modo que a amostra fosse composta de três pedaços de disco (Hoffmann et al., 2010). Por meio das medições de comprimento total do pseudocaule e dos raios de

Tabela 1. Médias mensais de temperatura média (TM), umidade relativa do ar (UR), coeficiente da cultura (Kc), evapotranspiração de referência (ETo), evapotranspiração da cultura (ETc), precipitação (Prec) e lâminas aplicadas, a cada 30 dias, desde os 30 até 540 dias após plantio (DAP).

\begin{tabular}{|c|c|c|c|c|c|c|c|c|c|c|}
\hline \multirow[t]{2}{*}{ DAP } & \multirow{2}{*}{$\begin{array}{l}\mathrm{TM} \\
\left({ }^{\circ} \mathrm{C}\right) \\
\end{array}$} & \multirow{2}{*}{$\begin{array}{l}\text { UR } \\
(\%) \\
\end{array}$} & \multirow[t]{2}{*}{$\mathrm{Kc}$} & \multirow[t]{2}{*}{ ETo } & \multirow{2}{*}{$\begin{array}{c}\text { ETc } \\
-(\mathrm{mm})--\end{array}$} & \multirow[t]{2}{*}{ Prec } & \multicolumn{4}{|c|}{ Lâmina d'água com base na \% da ETo (mm) } \\
\hline & & & & & & & 30 & 60 & 90 & 120 \\
\hline$\overline{30}$ & 23 & 89 & 0,47 & 90,4 & 34,2 & 107,3 & 34,2 & 34,2 & 34,2 & 34,2 \\
\hline 60 & 23 & 85 & 0,55 & 104,2 & 46,0 & 66,1 & 46,0 & 46,0 & 46,0 & 46,0 \\
\hline 90 & 25 & 82 & 0,64 & 128,3 & 66,1 & 70,3 & 66,1 & 66,1 & 66,1 & 66,1 \\
\hline 120 & 26 & 82 & 0,81 & 133,4 & 86,3 & 84,6 & 41,4 & 61,6 & 77,8 & 95,9 \\
\hline 150 & 27 & 75 & 0,95 & 156,5 & 118,3 & 9,9 & 67,8 & 84,7 & 103,4 & 124,1 \\
\hline 180 & 28 & 73 & 1,06 & 164,2 & 139,0 & 13,7 & 68,6 & 87,8 & 107,2 & 129,7 \\
\hline 210 & 27 & 76 & 1,11 & 160,1 & 142,1 & 26,9 & 61,4 & 82,6 & 100,0 & 122,8 \\
\hline 240 & 28 & 75 & 0,99 & 139,5 & 110,2 & 34,8 & 45,0 & 66,0 & 86,1 & 111,2 \\
\hline 270 & 28 & 79 & 0,90 & 142,0 & 102,3 & 112,3 & 55,2 & 71,3 & 89,5 & 109,7 \\
\hline 300 & 26 & 88 & 1,15 & 100,8 & 92,7 & 246,7 & 68,6 & 78,3 & 88,4 & 98,7 \\
\hline 330 & 25 & 87 & 1,15 & 96,5 & 88,8 & 57,7 & 48,9 & 58,5 & 69,0 & 80,2 \\
\hline 360 & 23 & 87 & 1,15 & 80,4 & 74,0 & 95,7 & 47,7 & 59,4 & 72,3 & 86,4 \\
\hline 390 & 22 & 91 & 1,15 & 79,6 & 73,3 & 264,3 & 73,3 & 73,3 & 73,3 & 73,3 \\
\hline 420 & 22 & 87 & 1,15 & 99,5 & 91,6 & 180,7 & 91,6 & 91,6 & 91,6 & 91,6 \\
\hline 450 & 23 & 83 & 1,15 & 112,8 & 103,8 & 171,0 & 103,8 & 103,8 & 103,8 & 103,8 \\
\hline 480 & 26 & 82 & 1,15 & 138,8 & 127,7 & 34,6 & 69,0 & 90,0 & 110,6 & 130,3 \\
\hline 510 & 27 & 74 & 1,15 & 156,5 & 144,0 & 4,9 & 51,1 & 81,1 & 112,0 & 136,2 \\
\hline 540 & 27 & 78 & 1,15 & 104,2 & 95,9 & 107,1 & 47,4 & 65,6 & 85,5 & 92,0 \\
\hline Total & - & - & - & $2.187,7$ & $1.736,3$ & $1.688,6$ & $1.087,1$ & $1.301,9$ & $1.516,8$ & $1.732,2$ \\
\hline
\end{tabular}


cada disco, calculou-se o volume total do pseudocaule, com uso da equação de volume de tronco de cone, $\mathrm{V}_{\mathrm{p}}=0,33 \pi \mathrm{h} \times\left[\mathrm{R}^{2}+(\mathrm{R} \times \mathrm{r})+\mathrm{r}^{2}\right]$, em que: $\mathrm{V}_{\mathrm{p}}$ é o volume do pseudocaule $\left(\mathrm{m}^{3}\right)$; h é a altura do pseudocaule $(\mathrm{m})$; $\mathrm{R}$ é o raio da base maior do pseudocaule (m); e r é o raio da base menor do pseudocaule $(\mathrm{m})$. Após obter o volume total, a massa de matéria seca foi determinada pela relação volume e massa de matéria seca dos discos.

A matéria seca total das folhas foi determinada por meio de coletas quinzenais das folhas senescentes, desde o início do ciclo. No entanto, para determinação do potássio, foram utilizadas amostras apenas das folhas que se encontravam na planta no momento da colheita (Moreira \& Fageria, 2009). As demais folhas coletadas foram descartadas após determinação da matéria seca.

Para determinação da massa de matéria seca das pencas, consideraram-se os pesos fresco e seco de dois frutos centrais por penca, de três pencas por cacho (primeira, quarta e sétima pencas), com resultados utilizados para estimar a massa de matéria seca total das pencas. Do engaço, retiraram-se três discos de 0,1 m de espessura, um de cada extremidade e outro do meio, para avaliação dos teores de nutrientes. Os discos foram pesados na forma fresca e seca, e a massa de matéria seca total foi obtida pela relação com o peso fresco total do engaço. O coração foi retirado após a formação total da última penca útil do cacho e, em seguida, foi pesado e levado para estufa, para determinação da matéria seca.

Os dados foram submetidos à análise de variância (teste F), e as médias entre lâminas foram comparadas pelo teste de Tukey, a 5\% de probabilidade, com uso do programa Sisvar (Ferreira, 2008). Os gráficos foram confeccionados com base no aplicativo Table Curve 2D (Systat, 2002).

\section{Resultados e Discussão}

A precipitação total foi maior do que as menores lâminas aplicadas. Entretanto, apesar dessa superioridade, a irrigação foi utilizada na maior parte do tempo, uma vez que a distribuição das chuvas foi irregular durante grande parte do ciclo. As precipitações supriram as necessidades hídricas da bananeira apenas no início do cultivo, até os 90 dias após o plantio (DAP) e entre 361 e 450 DAP, com precipitação total de $859,7 \mathrm{~mm}$ (Tabela 1$)$.
A altura de planta, o diâmetro do pseudocaule e a área foliar no florescimento foram influenciados significativamente pelas lâminas de irrigação, o que não ocorreu para o número de folhas por planta (Tabela 2). As doses de $\mathrm{K}$ não afetaram significativamente as variáveis, apesar da variação observada nos teores de $\mathrm{K}$ na solução do solo, ao longo do tempo, a 0,3 e a $0,7 \mathrm{~m}$ de profundidade (Figura 1). Possivelmente, o teor de $\mathrm{K}$ no solo, de $0,24 \mathrm{cmol}_{\mathrm{c}} \mathrm{dm}^{-3}$, foi suficiente para suprir as necessidades da planta no primeiro ciclo. A interação entre doses de potássio x lâminas

Tabela 2. Médias das variáveis de crescimento vegetativo e de produção, sob lâminas de irrigação aplicadas ${ }^{(1)}$.

\begin{tabular}{lcccccccc}
\hline $\begin{array}{l}\text { ETc } \\
(\mathrm{mm})\end{array}$ & $\begin{array}{c}\text { ALP } \\
(\mathrm{m})\end{array}$ & $\begin{array}{c}\text { DIP } \\
(\mathrm{m})\end{array}$ & $\begin{array}{c}\text { AFF } \\
\left(\mathrm{m}^{2}\right)\end{array}$ & NFP & NPC & NFC & $\begin{array}{c}\text { PRO } \\
\left(\mathrm{Mg} \mathrm{ha}^{-1}\right)\end{array}$ & $\begin{array}{c}\text { EUA } \\
\left(\mathrm{kg} \mathrm{mm}^{-1}\right)\end{array}$ \\
\hline 1.087 & $2,125 \mathrm{a}$ & $0,197 \mathrm{a}$ & $9,29 \mathrm{a}$ & $12,58 \mathrm{a}$ & $7,17 \mathrm{a}$ & $97,83 \mathrm{a}$ & $16,35 \mathrm{a}$ & $15,04 \mathrm{~b}$ \\
1.302 & $2,458 \mathrm{~b}$ & $0,225 \mathrm{~b}$ & $11,99 \mathrm{~b}$ & $13,67 \mathrm{a}$ & $7,83 \mathrm{a}$ & $112,41 \mathrm{~b}$ & $19,85 \mathrm{~b}$ & $15,24 \mathrm{~b}$ \\
1.517 & $2,449 \mathrm{~b}$ & $0,226 \mathrm{~b}$ & $12,26 \mathrm{~b}$ & $14,01 \mathrm{a}$ & $7,92 \mathrm{a}$ & $118,41 \mathrm{~b}$ & $20,54 \mathrm{~b}$ & $13,54 \mathrm{ab}$ \\
1.732 & $2,470 \mathrm{~b}$ & $0,229 \mathrm{~b}$ & $12,01 \mathrm{~b}$ & $13,58 \mathrm{a}$ & $7,67 \mathrm{a}$ & $116,91 \mathrm{~b}$ & $20,76 \mathrm{~b}$ & $11,99 \mathrm{a}$ \\
\hline $\mathrm{CV}(\%)$ & 7,90 & 6,98 & 19,16 & 8,23 & 10,05 & 10,72 & 14,07 & 13,33 \\
\hline
\end{tabular}

${ }^{(1)}$ Médias seguidas de letras iguais não diferem entre si pelo teste de Tukey, a $5 \%$ de probabilidade. ETc, evapotranspiração da cultura; ALP, altura do pseudocaule; DIP, diâmetro do pseudocaule; AFF, área foliar no florescimento; NFP, número de folhas por planta; NPC, número de pencas por cacho; NFC, número de frutos por cacho; PRO, produtividade; e EUA, eficiência do uso da água.

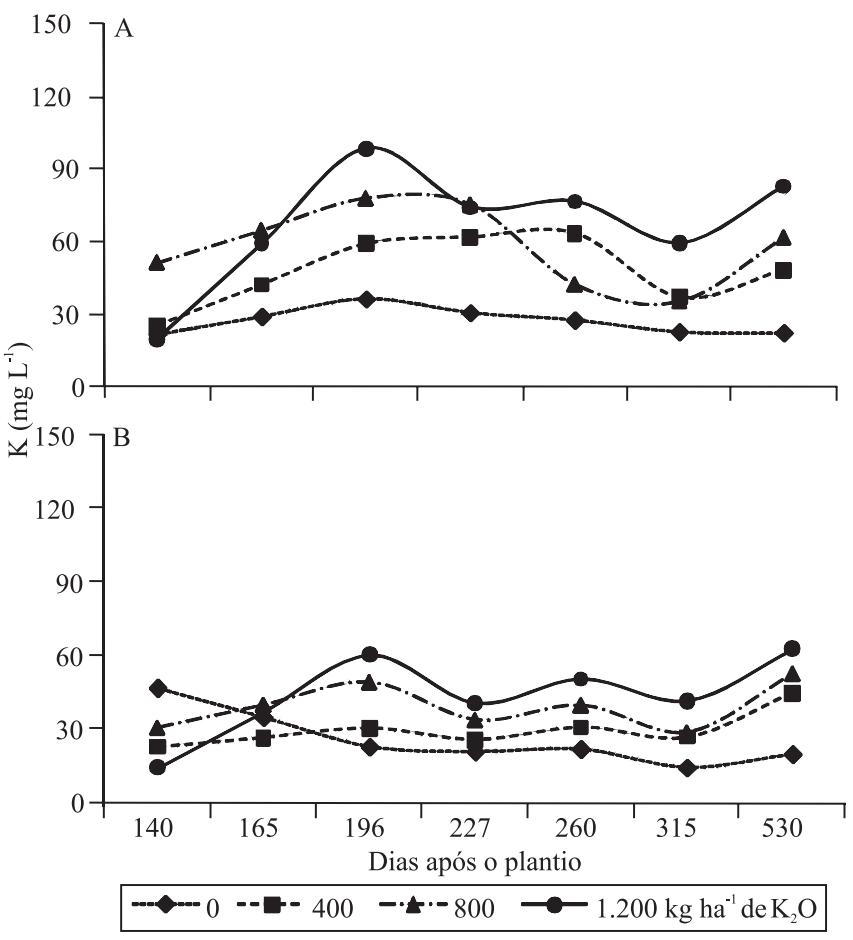

Figura 1. Teores de potássio na solução do solo em 0,3 (A) e $0,7 \mathrm{~m}$ (B) de profundidade, para quatro doses de fertilização potássica. 
de irrigação não influenciou significativamente as variáveis de crescimento vegetativo e de produção da planta.

Quanto à altura de planta, ao diâmetro do pseudocaule e à área foliar, houve crescimento acentuado entre as aplicações de 1.087 e $1.302 \mathrm{~mm}$ por ciclo de água (Tabela 2). Esta última lâmina apresentou resultados próximos aos das lâminas de 1.517 e $1.732 \mathrm{~mm}$ por ciclo, para as mesmas variáveis. As médias de diâmetro do pseudocaule observadas no presente trabalho foram semelhantes às obtidas por Melo et al. (2010a), para a cultivar Prata-Anã submetida a diferentes níveis de $\mathrm{N}$ e $\mathrm{K}$, com lâmina fixada em $100 \%$ da ETo. No entanto, Figueiredo et al. (2007) não observaram efeito significativo de lâminas de irrigação sobre diâmetro, comprimento do pseudocaule ou área foliar da bananeira 'Prata-Anã'.

A menor lâmina aplicada (1.087 $\mathrm{mm}$ por ciclo) apresentou os menores incrementos para as variáveis de crescimento, o que pode ser atribuído à redução média de $42 \%$ da água disponível do solo (AD), entre os 124 e os 198 DAP, e de $54 \%$, entre os 200 e os 230 DAP, com o uso desta lâmina, tendo-se estabelecido intervalo de deficit hídrico de 106 dias (Figura 2). Entre os 240 e 270 DAP, a umidade no solo permaneceu próxima ou acima da capacidade de campo (CC) para todas as lâminas, em função do aumento da precipitação nesse período (Tabela 1 e Figura 2).
As chuvas também interferiram significativamente na umidade do solo nos demais dias do ciclo (271 a 540 DAP). A menor lâmina manteve reduções acima de $20 \%$ da $\mathrm{AD}$, para a maioria dos dias. Entretanto, as demais lâminas oscilaram próximas à $\mathrm{CC}$ ou apresentaram reduções na AD inferiores a 20\%, o que justifica o fato de a lâmina de $1.302 \mathrm{~mm}$ por ciclo apresentar resultados de crescimento e de produção semelhantes aos encontrados pelas lâminas maiores. De acordo com Robinson \& Alberts (1986), o início do estresse na bananeira ocorre quando há redução de $20 \%$ da água disponível do solo. Segundo Turner et al. (2007), o deficit hídrico para bananeira promove redução da clorofila e morte prematura das folhas, $o$ que retarda o crescimento e, consequentemente, a produção da planta.

Houve aumento significativo da produtividade e do número de frutos por cacho com o aumento da menor para as maiores lâminas de irrigação. Contudo, os rendimentos proporcionados para essas variáveis pelas lâminas de 1.302 a $1.732 \mathrm{~mm}$ por ciclo não diferiram significativamente pelo teste de Tukey, a 5\% de probabilidade. As diferentes lâminas também não promoveram efeito no número de pencas por cacho (Tabela 2).

As médias de produtividade e de número de frutos por cacho para lâminas acima de $1.302 \mathrm{~mm}$ não diferiram significativamente $(\mathrm{p}>0,05)$, o que indica que os incrementos de lâmina de água acima deste

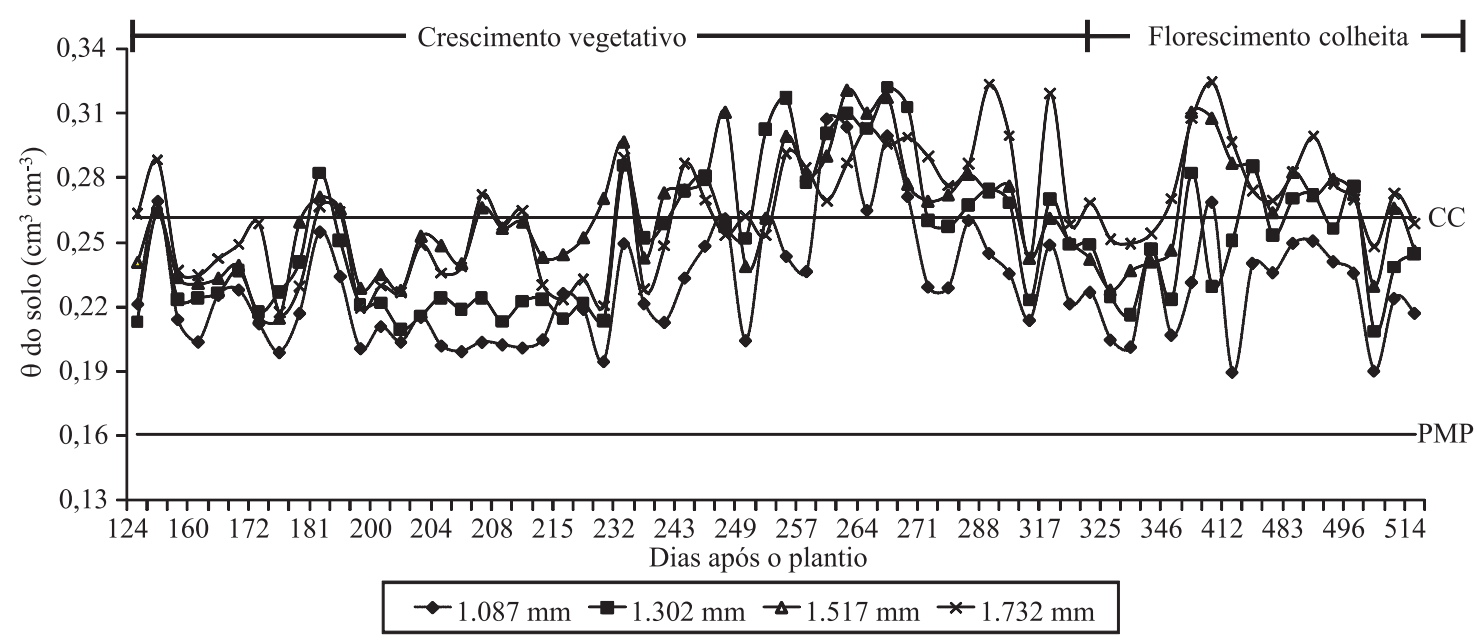

Figura 2. Balanço hídrico no solo para cada lâmina d'água aplicada no decorrer do ciclo da cultura, obtido a 0,3 m de profundidade por meio de reflectômetro TDR. CC, capacidade de campo; PMP, ponto de murcha permanente. 
valor não trouxeram incrementos significativos para essas variáveis. Coelho et al. (2006) não observaram diferença na produtividade da bananeira 'Prata-Anã'com o aumento de 100 para $120 \%$ da ETo. Para essa mesma cultivar, conduzida durante o primeiro ciclo, Fehlauer et al. (2010) e Fernandes et al. (2008) encontraram, para a lâmina de $120 \%$ da ETo, produtividades semelhantes às observadas no presente trabalho com a lâmina de $60 \%$ da ETo (1.302 $\mathrm{mm}$ por ciclo). Contudo, Melo et al. (2010a) obtiveram produtividades superiores nas mesmas condições de cultivo e de dosagens de $\mathrm{K}_{2} \mathrm{O}$ com a aplicação de $100 \%$ da ETo, para a cultivar Prata-Anã.

As doses de $\mathrm{K}_{2} \mathrm{O}$ não influenciaram significativamente as variáveis de produção. Diversos autores também não observaram efeito da fertilização potássica na maioria das variáveis produtivas no primeiro ciclo de bananeiras do grupo Prata, sob diferentes condições edafoclimáticas (Silva et al., 2003; Pinto et al., 2005; Crisostomo et al., 2008).

A eficiência do uso da água (EUA) obtida com a aplicação de $1.302 \mathrm{~mm}$ por ciclo não diferiu da observada com a lâmina de $1.517 \mathrm{~mm}$ por ciclo e foi significativamente superior à encontrada com a de $1.732 \mathrm{~mm}$ por ciclo (Tabela 2). Dessa forma, a lâmina de $1.302 \mathrm{~mm}$ por ciclo pode ser considerada como a mais adequada para a bananeira 'Galil 18', para as condições edafoclimáticas avaliadas, uma vez que apresentou comportamento semelhante ou superior ao das maiores lâminas testadas, quanto a crescimento vegetativo e produção.

Não houve efeito das doses de $\mathrm{K}_{2} \mathrm{O}$ no acúmulo de $\mathrm{K}$ ou na massa de matéria seca dos diferentes órgãos da parte aérea da bananeira. As lâminas de irrigação influenciaram, de forma significativa, a absorção total de $\mathrm{K}$ para os diversos órgãos em estudo (Tabela 3 ).

$\mathrm{O}$ acúmulo de $\mathrm{K}$ na parte aérea com a aplicação de $1.302 \mathrm{~mm}$ por ciclo resultou na absorção de $773,6 \mathrm{~kg} \mathrm{ha}^{-1}$, o que não diferiu dos resultados obtidos com as lâminas de 1.517 e $1.732 \mathrm{~mm}$ por ciclo. Já a lâmina de $1.087 \mathrm{~mm}$ por ciclo proporcionou as menores importações de K (497,9 $\left.\mathrm{kg} \mathrm{ha}^{-1}\right)$.

$\mathrm{O}$ cacho (pencas + engaço) acumulou $25 \%$ do $\mathrm{K}$ total absorvido pela parte aérea, com a absorção de $185,6 \mathrm{~kg} \mathrm{ha}^{-1}$ e aplicação de $1.302 \mathrm{~mm}$ por ciclo, não tendo diferido significativamente das maiores lâminas avaliadas (Tabela 3). A aplicação de $1.087 \mathrm{~mm}$ por ciclo proporcionou absorção de $144,2 \mathrm{~kg} \mathrm{ha}^{-1}$ de $\mathrm{K}$, o que corresponde à redução de 34\% na média de absorção do nutriente observada com as maiores lâminas. Moreira \& Fageria (2009) observaram, para a cultivar Thap Maeo, acúmulo total de $1.265 \mathrm{~kg} \mathrm{ha}^{-1}$ de K. De acordo com estes autores, os cachos importaram do solo, aproximadamente, $21 \%$ do total de $\mathrm{K}$ absorvido pela planta, valor próximo aos obtidos no presente trabalho.

A variação no acúmulo de $\mathrm{K}$ nos órgãos avaliados ocorreu em função do total de matéria seca produzida, que variou em função das diferentes lâminas (Tabela 3 ). As maiores quantidades de $\mathrm{K}$ acumulado na parte aérea foram proporcionadas pelas aplicações de 1.302, 1.517 e $1.732 \mathrm{~mm}$ por ciclo (Tabela 3 ).

O pseudocaule acumulou $264 \mathrm{~g}(54,6 \%)$ do total de $\mathrm{K}$ absorvido pela parte aérea, com a aplicação de $1.302 \mathrm{~mm}$ por ciclo, não tendo diferido dos acúmulos proporcionados pelas lâminas de 1.517 e $1.732 \mathrm{~mm}$ por ciclo. Sequencialmente, as folhas e as pencas apresentaram resposta semelhante ao pseudocaule, com a lâmina de $1.032 \mathrm{~mm}$ por ciclo, não tendo diferido significativamente das maiores lâminas avaliadas. Já os acúmulos de K pelo engaço e pelo coração diferiram apenas entre as lâminas de 1.087 para $1.732 \mathrm{~mm}$ por ciclo (Tabela 3). Os resultados do pseudocaule estão de acordo com os de Moreira \& Fageria (2009), em estudo com a cultivar Thap Maeo na Amazônia Ocidental. Esses autores observaram que o órgão representou o maior acúmulo de K na parte aérea da planta, com $75 \%$ do total acumulado.

Tabela 3. Produção de matéria seca e acúmulo e absorção de $\mathrm{K}$, em função da aplicação de lâminas d'água, na cultivar de bananeira Galil $18^{(1)}$.

\begin{tabular}{llllllll}
\hline $\begin{array}{l}\text { Lâmina } \\
\text { (mm) }\end{array}$ & Pseudocaule & Folhas & Engaço & Pencas & Coração Parte aérea \\
\hline \multicolumn{7}{c}{ Massa de matéria seca (g por órgão) } \\
1.087 & $1.260,9 \mathrm{a}$ & $3.240,1 \mathrm{a}$ & $144,8 \mathrm{a}$ & $1.794,4 \mathrm{a}$ & $98,8 \mathrm{a}$ & $6.539,0 \mathrm{a}$ \\
1.302 & $2.058,9 \mathrm{~b}$ & $3.660,6 \mathrm{~b}$ & $177,3 \mathrm{ab}$ & $2.266,9 \mathrm{~b}$ & $134,1 \mathrm{~b}$ & $8.297,8 \mathrm{~b}$ \\
1.517 & $1.783,1 \mathrm{ab}$ & $3.894,6 \mathrm{~b}$ & $207,4 \mathrm{~b}$ & $2.390,9 \mathrm{~b}$ & $138,3 \mathrm{~b}$ & $8.414,3 \mathrm{~b}$ \\
1.732 & $1.962,5 \mathrm{~b}$ & $3.833,5 \mathrm{~b}$ & $197,3 \mathrm{~b}$ & $2.384,4 \mathrm{~b}$ & $165,9 \mathrm{c}$ & $8.543,6 \mathrm{~b}$ \\
\hline \multicolumn{7}{c}{ Acúmulo de K (g por órgão) } \\
1.087 & $140,2 \mathrm{a}$ & $68,4 \mathrm{a}$ & $19,1 \mathrm{a}$ & $71,1 \mathrm{a}$ & $12,5 \mathrm{a}$ & $311,2 \mathrm{a}$ \\
1.302 & $264,1 \mathrm{~b}$ & $86,1 \mathrm{~b}$ & $23,6 \mathrm{ab}$ & $92,4 \mathrm{~b}$ & $17,2 \mathrm{ab}$ & $483,5 \mathrm{~b}$ \\
1.517 & $226,4 \mathrm{ab}$ & $86,0 \mathrm{~b}$ & $26,0 \mathrm{ab}$ & $96,9 \mathrm{~b}$ & $16,9 \mathrm{ab}$ & $451,7 \mathrm{~b}$ \\
1.732 & $248,9 \mathrm{~b}$ & $88,5 \mathrm{~b}$ & $26,1 \mathrm{~b}$ & $95,4 \mathrm{~b}$ & $19,4 \mathrm{~b}$ & $479,0 \mathrm{~b}$ \\
\hline \multicolumn{7}{c}{ Absorção de K $\left(\mathrm{kg} \mathrm{ha}{ }^{-1}\right)$} \\
1.087 & $224,7 \mathrm{a}$ & $109,4 \mathrm{a}$ & $30,5 \mathrm{a}$ & $113,7 \mathrm{a}$ & $20,1 \mathrm{a}$ & $497,9 \mathrm{a}$ \\
1.302 & $422,6 \mathrm{~b}$ & $137,8 \mathrm{~b}$ & $37,8 \mathrm{ab}$ & $147,8 \mathrm{~b}$ & $27,6 \mathrm{ab}$ & $773,6 \mathrm{~b}$ \\
1.517 & $362,2 \mathrm{ab}$ & $137,6 \mathrm{~b}$ & $41,6 \mathrm{ab}$ & $154,2 \mathrm{~b}$ & $27,0 \mathrm{ab}$ & $722,7 \mathrm{~b}$ \\
1.732 & $398,3 \mathrm{~b}$ & $141,7 \mathrm{~b}$ & $41,8 \mathrm{~b}$ & $153,4 \mathrm{~b}$ & $31,1 \mathrm{~b}$ & $766,4 \mathrm{~b}$ \\
\hline
\end{tabular}

${ }^{(1)}$ Médias seguidas de letras iguais, nas colunas, não diferem pelo teste de Tukey, a 5\% de probabilidade. 


\section{Conclusões}

1. A lâmina de água de $1.302 \mathrm{~mm}$ por ciclo promove alta produtividade e maximiza a eficiência do uso da água para a cultivar Galil 18, nos Tabuleiros Costeiros da Bahia.

2. As folhas produzem a maior quantidade de matéria seca na parte aérea da bananeira 'Galil 18' durante o ciclo.

3. Os cachos importam $25 \%$ do total de $\mathrm{K}$ absorvido do solo pela planta, e o pseudocaule é o órgão da parte aérea que mais acumula $\mathrm{K}$.

\section{Referências}

ALLEN, R.G.; PEREIRA, L.S.; RAES, D.; SMITH, M. Crop evapotranspiration: guidelines for computing crop water requirements. Roma: FAO, 1998. 300p. (FAO. Irrigation and drainage paper, 56).

AZEVEDO, J.H.O. de; BEZERRA, F.M.L. Resposta de dois cultivares de bananeira a diferentes lâminas de irrigação. Ciência Agronômica, v.39, p.28-33, 2008.

BARROSO, A. de A.F.; VIANA, T.V. de A.; MARINHO, A.B.; COSTA, S.C.; AZEVEDO, B.M. de. Teores de macronutrientes em folhas de bananeira cv. Pacovan Apodi, sob lâminas de irrigação e doses de potássio. Engenharia Agrícola, v.31, p.529-538, 2011.

BORGES,A.L.; OLIVEIRA,A.M.G. Nutrição, calagem e adubação. In: CORDEIRO, Z.J.M. (Org.). Banana produção: aspectos técnicos. Brasília: Embrapa Comunicação para Transferência de Tecnologia, 2000. p.47-59.

BRAGA FILHO, J.R.; NASCIMENTO, J.L. do; NAVES, R.V.; SILVA, L.B. e; PEREIRA, A.C. da C.P.; GONÇALVES, H.M.; RODRIGUES, C. Crescimento e desenvolvimento de cultivares de bananeira irrigadas. Revista Brasileira de Fruticultura, v.30, p.981-988, 2008.

COELHO, E.F.; LEDO, C.A. da S.; SILVA, S. de O. Produtividade da bananeira 'Prata-Anã' e 'Grande Naine' no terceiro ciclo sob irrigação por microaspersão em tabuleiros costeiros da Bahia. Revista Brasileira de Fruticultura, v.28, p.435-438, 2006.

CRISOSTOMO, L.A.; MONTENEGRO, A.A.T.; SOUSA NETO, J. de; LIMA, R.N. de. Influência da adubação NPK sobre a produção e qualidade dos frutos de bananeira cv. "Pacovan". Revista Ciência Agronômica, v.39, p.45-52, 2008.

FEHLAUER, T.J.; RODRIGUES-OTUBO, B.M.; SANDRINI, M.; DESTRO, D. Caracterização da produção de genótipos de banana introduzidos na região de Bonito - MS. Revista Brasileira de Fruticultura, v.32, p.938-943, 2010.

FERNANDES, L.A.; RAMOS, S.J.; VALADADRES, S.V.; LOPES, P.S.N.; FAQUIN, V. Fertilidade do solo, nutrição mineral e produtividade da bananeira irrigada por dez anos. Pesquisa Agropecuária Brasileira, v.43, p.1575-1581, 2008.

FERREIRA, D.F. SISVAR: um programa para análise e ensino de estatística. Revista Symposium, v.6, p.36-41, 2008.
FIGUEIREDO, F.P. de; FARIA, M.A. de; OLIVEIRA, F.G. Efeito de diferentes lâminas d'água e percentagens de área umedecida sobre o desenvolvimento vegetativo e produção da bananeira (Musa sp.) cultivar Prata-Anã. Revista Ceres, v.54, p.125-131, 2007.

FOOD AND AGRICULTURE ORGANIZATION OF THE UNITED NATIONS. Faostat. Available at: $<$ http://faostat.fao.org/ site/567/DesktopDefault.aspx?PageID=567\#ancor $>$. Accessed on: 6 Feb. 2011.

HOFFMANN, R.B.; OLIVEIRA, F.H.T. de; SOUZA, A.P. de; GHEYI, H.R.; SOUZA JÚNIOR, R.F. de. Acúmulo de matéria seca e de macronutrientes em cultivares de bananeira irrigada. Revista Brasileira de Fruticultura, v.32, p.268-275, 2010.

JAIMEZ, R.E.; RADA, F.; GARCÍA-NÚÑEZ, A.; AZÓCAR, A. Seasonal variations in leaf gas exchange of plantain cv. Hartón (Musa AAB) under different soil water conditions in a humid tropical region. Scientia Horticulturae, v.104, p.79-89, 2005.

MALAVOLTA, E.; VITTI, G.C.; OLIVEIRA, S.A. de. Avaliação do estado nutricional das plantas: princípios e aplicações. 2.ed. Piracicaba: Associação Brasileira para Pesquisa da Potassa e do Fosfato, 1997. 319p.

MELO, A.S. de; FERNANDES, P.D.; SOBRAL, L.F.; BRITO, M.E.B.; DANTAS, J.D.M. Crescimento, produção de biomassa e eficiência fotossintética da bananeira sob fertirrigação com nitrogênio e potássio. Revista Ciência Agronômica, v.41, p.417-426, 2010a.

MELO, A.S. de; SOBRAL, L.F.; FERNANDES, P.D.; BRITO, M.E.B.; VIÉGAS, P.R.A. Aspectos técnicos e econômicos da bananeira 'Prata-Anã' sob fertirrigação nos tabuleiros costeiros de Sergipe. Revista Ciência e Agrotecnologia, v.34, p.564-571, 2010b.

MOREIRA, A.; FAGERIA, N.K. Repartição e remobilização de nutrientes na bananeira. Revista Brasileira de Fruticultura, v.31, p.574-581, 2009.

NEVES, R.L.L.; FERREYRA, F.F.H.; MACIEL, R.F.P.; FROTA, J.N.E. Extração de nutrientes em banana (Musa sp.) cv. Pacovan. Ciência Agronômica, v.22, p.115-120, 1991.

OLIVEIRA, P.G.F. de; MOREIRA, O. da C.; BRANCO, L.M.C.; COSTA, R.N.T.; DIAS, C.N. Eficiência de uso dos fatores de produção água e potássio na cultura da melancia irrigada com água de reúso. Revista Brasileira de Engenharia Agrícola e Ambiental, v.16, p.153-158, 2012.

PINTO, J.M.; FARIA, C.M.B. de; SILVA, D.J.; FEITOSA FILHO, J.C. Doses de nitrogênio e potássio aplicadas via fertirrigação em bananeira. Irriga, v.10, p.46-52, 2005.

ROBINSON, J.C.; ALBERTS, A.J. Growth and yield responses of banana (cultivar 'Williams') to drip irrigation under drought and normal rainfall conditions in the subtropics. Scientia Horticulturae, v.30, p.187-202, 1986.

SANTOS, V.P. dos; FERNANDES, P.D.; MELO, A.S. de; SOBRAL, L.F.; BRITO, M.E.B.; DANTAS, J.D. de M.; BONFIM, L.V. Fertirrigação da bananeira cv. Prata-Anã com N e K em um Argissolo Vermelho-Amarelo. Revista Brasileira de Fruticultura, v.31, p.567-573, 2009. 
SILVA, J.T.A. da; BORGES, A.L.; CARVALHO, J.G.; DAMASCENO, J.E.A. Adubação com potássio e nitrogênio em três ciclos de produção da bananeira cv. Prata-Anã. Revista Brasileira de Fruticultura, v.25, p.152-155, 2003.

SOUZA, L. da S.; SOUZA, L.D. Caracterização físico-hídrica de solos da área do Centro Nacional de Pesquisa de Mandioca e Fruticultura Tropical. Cruz das Almas: Embrapa Mandioca e Fruticultura, 2001. 56p. (Embrapa Mandioca e Fruticultura. Boletim de pesquisa e desenvolvimento, 20).

SYSTAT. Table curve 2D and 3D. San José: MMIV Systat Software, 2002
TEIXEIRA, L.A.J.; QUAGGIO, J.A.; MELLIS, E.V. Ganhos de eficiência fertilizante em bananeira sob irrigação e fertirrigação.

Revista Brasileira de Fruticultura, v.33, p.272-278, 2011.

TURNER, D.W.; FORTESCUE, J.A.; THOMAS, D.S. Environmental physiology of the bananas (Musa spp.). Brazilian Journal of Plant Physiology, v.19, p.463-484, 2007.

ZUCOLOTO, M.; LIMA, J.S. de S.; COELHO, R.I. Modelo matemático para estimativa da área foliar total de bananeira 'Prata-Anã'. Revista Brasileira Fruticultura, v.30, p.1152-1154, 2008.

Recebido em 18 de agosto de 2011 e aprovado em 29 de janeiro de 2012 